\title{
Risk of dementia in patients with toxoplasmosis: a nationwide, population-based cohort study in Taiwan
}

\author{
Hung-Yi Yang ${ }^{1}$, Wu-Chien Chien ${ }^{2,3,4,5}$, Chi-Hsiang Chung ${ }^{2,3,5}$, Ruei-Yu Su' ${ }^{1}$, Chung-Yu Lai ${ }^{6}$, Chuan-Chi Yang ${ }^{7,8}$ and
} Nian-Sheng Tzeng $8,9^{*}$ (D)

\begin{abstract}
Background: Approximately 25-30\% of individuals worldwide are infected with Toxoplasma gondii (T. gondii), which is difficult to detect in its latent state. We aimed to evaluate the association between toxoplasmosis, the risk of dementia, and the effects of antibiotics in Taiwan.

Methods: This nationwide, population-based, retrospective cohort study was conducted using the Longitudinal Health Insurance Database containing the records of 2 million individuals retrieved from Taiwan's National Health Insurance Research Database. Fine-Gray competing risk analysis was used to determine the risk for the development of dementia in the toxoplasmosis cohort relative to the non-toxoplasmosis cohort. A sensitivity analysis was also conducted. The effects of antibiotics (sulfadiazine or clindamycin) on the risk of dementia were also analyzed.

Results: We enrolled a total of 800 subjects, and identified 200 patients with toxoplasmosis and 600 sex- and agematched controls without toxoplasmosis infection in a ratio of 1:3, selected between 2000 and 2015. The crude hazard ratio (HR) of the risk of developing dementia was 2.570 [95\% confidence interval $(\mathrm{Cl})=1.511-4.347, P<0.001]$. After adjusting for sex, age, monthly insurance premiums, urbanization level, geographical region, and comorbidities, the adjusted HR was $2.878(95 \% \mathrm{Cl}=1.709-4.968, P<0.001)$. Sensitivity analysis revealed that toxoplasmosis was associated with the risk of dementia even after excluding diagnosis in the first year and the first 5 years. The usage of sulfadiazine or clindamycin in the treatment of toxoplasmosis was associated with a decreased risk of dementia.
\end{abstract}

Conclusions: This finding supports the evidence that toxoplasmosis is associated with dementia and that antibiotic treatment against toxoplasmosis is associated with a reduced risk of dementia. Further studies are necessary to explore the underlying mechanisms of these associations.

Keywords: Toxoplasma gondii, Toxoplasmosis, Dementia, Taiwan

\section{Background}

Toxoplasmosis, which is caused by infection with the Toxoplasma gondii (T. gondii), parasite, affects about $25-30 \%$ of the population worldwide [1]. Individuals can become infected from the ingestion of tissue cysts,

\footnotetext{
*Correspondence: pierrens@mail.ndmctsgh.edu.tw

${ }^{8}$ Department of Psychiatry, Tri-Service General Hospital, School of Medicine, National Defense Medical Center, Taipei, Taiwan

Full list of author information is available at the end of the article
}

infected meat, or food contaminated with sporulated oocysts [1]. After ingestion, bradyzoites and sporozoites released from the cysts and oocysts eventually form tachyzoites [2], which can spread into the bloodstream and lymphatic system and cause distant organ invasion. The tachyzoites can then induce acute inflammation in the organs, which can lead to myocarditis, hepatitis, pneumonitis, or retinochoroiditis [2]. They can also cross the blood-brain barrier and invade the brain cells during original author(s) and the source, provide a link to the Creative Commons licence, and indicate if changes were made. The images or other third party material in this article are included in the article's Creative Commons licence, unless indicated otherwise in a credit line to the material. If material is not included in the article's Creative Commons licence and your intended use is not permitted by statutory regulation or exceeds the permitted use, you will need to obtain permission directly from the copyright holder. To view a copy of this licence, visit http://creativecommons.org/licenses/by/4.0/. The Creative Commons Public Domain Dedication waiver (http://creativeco mmons.org/publicdomain/zero/1.0/) applies to the data made available in this article, unless otherwise stated in a credit line to the data. 
the first week of infection [1]. In addition, chronic infection can occur by latent toxoplasmic cysts which remain in the tissues or the central nervous system (CNS) [1]. Elevated risk of cerebral toxoplasmosis has been noted in the elderly due to the possibility of increased immunosuppression [3]. In Taiwan, the Center for Disease Control lists the antibiotics sulfadiazine and clindamycin as treatment for toxoplasmosis [4].

Dementia is a common neurodegenerative disease characterized by symptoms of worsening cognition, emotional change, difficulties with language expression, and decreased motivation [5]. The most common cause is Alzheimer's disease (AD), and other common causes include buildup of Lewy bodies, frontotemporal lobe degeneration, and vascular disease [6]. The pathophysiology of $\mathrm{AD}$ is of major concern and is related to the amyloid $\beta(A \beta)$ protein and intracellular neurofibrillary tangles [7]. However, the inflammatory process can also be associated with neurodegenerative disorders such as AD, Parkinson's disease (PD), Huntington's disease (HD), amyotrophic lateral sclerosis (ALS), or multiple sclerosis (MS). Chronic inflammation can be induced by infectious agents including viruses (herpes simplex virus), bacteria (Chlamydia pneumonia), or parasites (T. gondii) $[8,9]$.

Several previous studies have shown that chronic toxoplasmic infection may be associated with human behavior alterations, obsessive-compulsive disorder, or even schizophrenia $[10,11]$. Infection can also lead to other neurodegenerative symptoms including memory impairment [12] and cognitive decline [13]. The cysts' location in the brain [14], the immune response [15], and changes in brain metabolism [16] can have effects on cognitive dysfunction. In recent years, two meta-analyses of several cross-sectional studies have reported results supporting an association between toxoplasmosis and the risk of $\mathrm{AD}$ $[17,18]$. However, a case-control study by Mahami et al. (2016) found no significant relationship between toxoplasmosis and AD [19], and Perry et al. found no difference in serum $T$. gondii antibody titers between an $\mathrm{AD}$ group and control group with latent toxoplasmosis [20]. No previous nationwide cohort studies have investigated the association among toxoplasmosis, antibiotic treatment, and the risk of dementia. Therefore, we conducted the present study using Taiwan's National Health Insurance Research Database (NHIRD) to investigate whether toxoplasmosis is associated with the risk of dementia, along with the role of antibiotic treatment in the risk of dementia in patients with toxoplasmic infections.

\section{Methods}

\section{Design and study methods}

This retrospective cohort study is based on the NHIRD, provided by the Health and Welfare Data Science Center
(HWDC), Ministry of Health and Welfare (MOHW), Taiwan. The National Health Insurance (NHI) scheme was established in 1995, and as of June 2009, it included contracts with $97 \%$ of medical providers, with approximately 23 million people enrolled in the program, or more than $99 \%$ of the entire population [21,22]. The details of this program have been documented in previous studies [2330]. The NHIRD registration files and the original claims data include overall data on personal information and disease coding.

The NHIRD also records inpatient care, ambulatory care, dental care, and prescription drugs received by the insured and their date of birth. Pursuant to the Personal Information Protection Act, individual identifiers are encrypted before the release of data for research. In the present study, patients diagnosed with toxoplasmosis during the period 2000-2015 were enrolled, and those recorded in the NHI program were coded according to the International Classification of Diseases, Ninth Revision, Clinical Modification (ICD-9-CM), as ICD-9 codes of 130 .

All diagnoses of dementia were made by board-certified psychiatrists or neurologists. Toxoplasmosis was confirmed by serum antibody screening and avidity test or polymerase chain reaction (PCR) [4]. Several previous studies have revealed high accuracy and validity of the diagnoses in the NHIRD [31-33], and licensed medical records technicians verify the coding before reimbursement claims can proceed for hospitals and clinics [34]. Furthermore, the NHI Administration appoints several senior external specialists in psychiatry, neurology, infectious disease, and other related medical specialties for random review of the records of ambulatory care visits and inpatient claims to verify the accuracy of the diagnoses [35]. Thus, the NHIRD records are suitable for examining the longitudinal association between toxoplasmosis and the potential risk of subsequent development of dementia.

\section{Ethical approval}

This study was approved by the Institutional Review Board of the Tri-Service General Hospital (TSGH IRB No. 2-107-05-026). Because the patient identifiers were encrypted before their data were used for research purposes in order to protect confidentiality, the requirement for written or verbal consent from patients for data linkage was waived.

\section{Study population}

This was a retrospective cohort study. From the Longitudinal Health Insurance Database (LHID) including 2 million individuals, a randomly stratified sub-database retrieved from the NHIRD was used to identify 


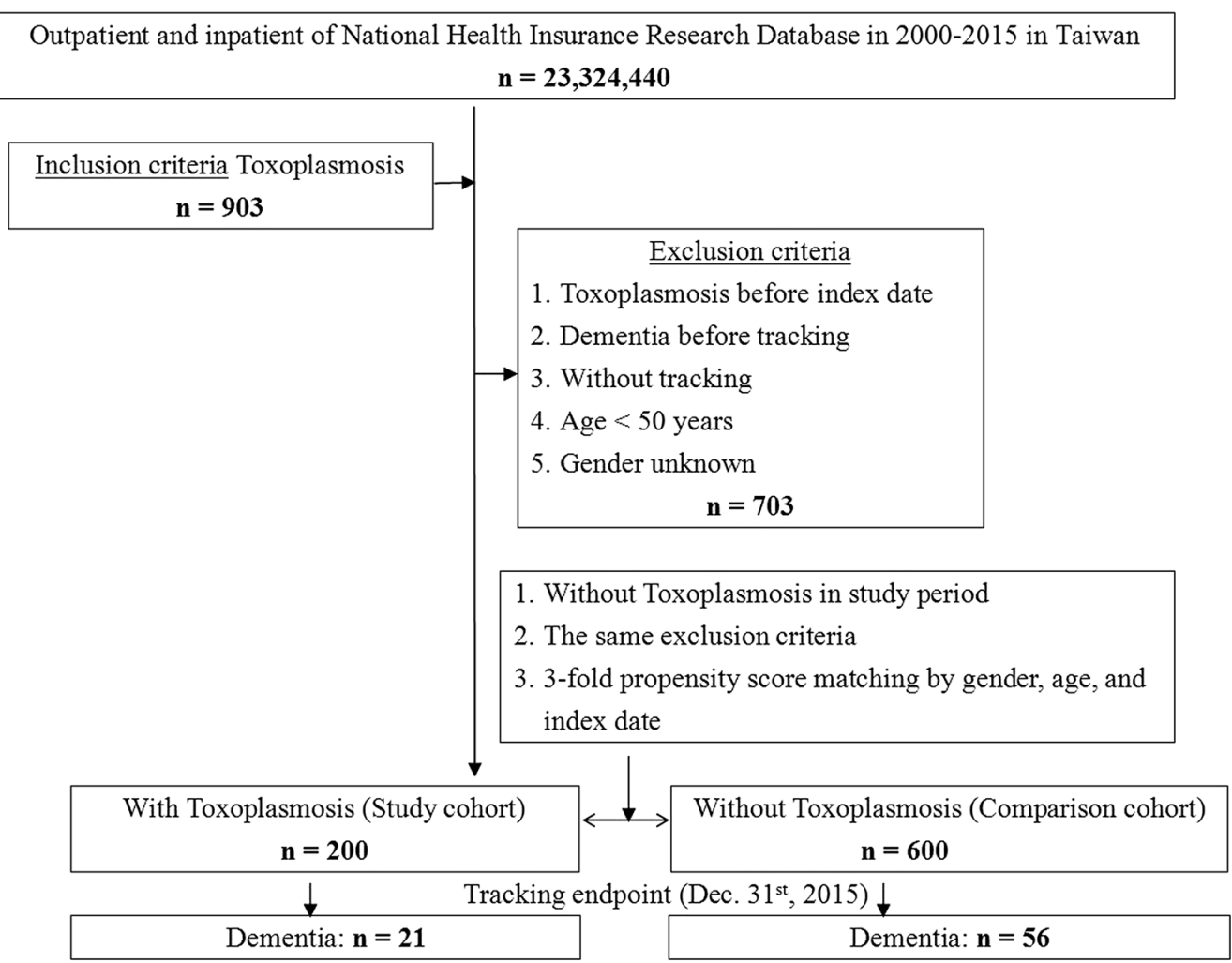

Fig. 1 The flowchart of study sample selection

individuals $\geq 50$ years of age with a diagnosis of toxoplasmosis during the period between January 1, 2000, and December 31, 2015, according to ICD-9-CM code 130.x. In this 15-year follow-up study, patients were excluded if they were diagnosed with dementia or toxoplasmosis before 2000, were diagnosed with dementia before the first visit for toxoplasmosis, or were aged $<50$. The date of toxoplasmosis diagnosis was defined as the index date. Figure 1 depicts the flowchart of this study for the comparison of patients with toxoplasmosis and controls. In addition, a flowchart of the study for the comparison of patients with toxoplasmosis with and without antibiotic treatment is presented in Additional file 1: Figure S1.

\section{Covariates}

The covariates included sex, age group (50$64, \geq 65$ years), geographical area of residence (northern, central, southern, or eastern Taiwan), urbanization level of residence (levels 1 to 4), levels of hospitals as medical centers, regional or local hospitals, and monthly income (in New Taiwan dollars [NT\$]: $<18,000,18,000-$ $34,999, \geq 35,000$ ). The urbanization level of residence was defined according to the population, along with various indicators of the level of political, economic, cultural, and metropolitan development. Level 1 was defined as a population of $>1,250,000$, and a specific designation of significant political, economic, cultural, and metropolitan development. Level 2 was defined as a population between 500,000 and 1,249,999, and as playing an important role in the political system, economy, and culture. Urbanization levels 3 and 4 were defined as a population between 149,999 and 499,999, and < 149,999, respectively.

The comorbidities in this study were diabetes mellitus (DM), hypertension, hyperlipidemia, coronary artery disease (CAD), human immunodeficiency virus (HIV) infection/acquired immunodeficiency syndrome (AIDS), and other immune deficiency diseases. All the ICD codes of the comorbidities are as listed in Additional file 3: Table S1.

Data on the usage of the antibiotics sulfadiazine and clindamycin were collected. The data on the defined daily dose (DDD) were obtained from the WHO Collaborating Centre for Drug Statistics Methodology (https://www. whocc.no/), and the duration of antibiotics usage was calculated by dividing the cumulative doses by the DDD of the antibiotics. We analyzed the effects on the risk of dementia between the two subgroups with or without the antibiotics treatment, with the sample divided by the covariates with the references of previous studies using the NHIRD, regarding the treatment effects of 
medications [36-38]. The yearly times of the visits to psychiatry, neurology, and infection medicine clinics were also recorded.

\section{Study outcomes}

All the participants were followed from the index date until the onset of dementia, withdrawal from the NHIRD, or the end of 2015. The patients with dementia were grouped into those with Alzheimer's disease (AD), vascular dementia $(\mathrm{VaD})$, or other types of dementia. At least three visits in one consecutive year in the NHIRD records would be regarded as a diagnosis of dementia. All the ICD codes of dementia are as listed in Additional file 3: Table S1.

\section{Statistical analysis}

All analyses were performed using SPSS software version 22 (IBM Corp., Armonk, NY, USA). Chi-square and $t$-tests were used to evaluate the distribution of the categorical and continuous variables, respectively. The Fisher exact test for categorical variables was used to statistically examine the differences between the two cohorts. FineGray survival analysis was used to determine the risk of dementia, and the results are presented as a hazard ratio (HR) with a 95\% confidence interval (CI). A sensitivity analysis excluding the diagnosis of dementia both within the first year and the first 5 years was conducted to avoid protopathic bias. The difference in the risk of dementia between the toxoplasmosis subjects and control groups was estimated using the Kaplan-Meier method with the log-rank test. A two-tailed $P$-value $<0.05$ was considered to indicate statistical significance.

\section{Results}

\section{Sample characteristics}

Table 1 shows that a total of 800 patients were enrolled, including 200 subjects with toxoplasmosis and 600 controls without toxoplasmosis, which were matched 1:3 for age, sex, and index year. There were no differences in sex or age. The toxoplasmosis cohort tended to have a higher percentage of comorbidities of DM, but a slightly lower percentage of HIV/AIDS and other immunodeficiency diseases, in comparison to the non-toxoplasmosis controls. The patients with toxoplasmosis tended to have monthly insurance premiums of NT\$18,000-34,999, lived in central and eastern Taiwan and the outlying islands, resided in areas of level 2, 3, and 4 urbanization, and sought medical care from the medical center and regional hospital. In addition, patients with toxoplasmosis visited more clinics of infectious disease and neurology than the control group.
Kaplan-Meier model for the cumulative incidence of dementia

Of the toxoplasmosis patients, 21/200 (457.84 per $10^{5}$ person-years) developed dementia, as compared to $56 / 600$ (323.42 per $10^{5}$ person-years) in the control group, and the difference was statistically significant in Kaplan-Meier survival analysis (log-rank, $P=0.030$, Fig. 2).

Of the toxoplasmosis patients, 20/191 with antibiotic treatment (455.72 per $10^{5}$ person-years) developed dementia, as compared to $1 / 9$ without antibiotic treatment (507.67 per $10^{5}$ person-years) in the control group, and the difference was statistically significant in the Kaplan-Meier survival analysis (log-rank, $P=0.099$, Additional file 2: Figure S2).

\section{HR analysis of dementia in patients with toxoplasmosis}

Table 2 shows that Fine-Gray competing risk model analysis revealed that the study subjects were more likely to develop psychiatric disorders (crude hazard ratio [HR]: 2.570, 95\% CI $=1.511-4.347, P<0.001)$. After adjusting for gender, age, monthly insurance premiums, urbanization level, geographical region, and comorbidities, the adjusted HR was $2.878(95 \% \mathrm{CI}=1.709-4.968, P<0.001)$. Male gender and higher Charlson Comorbidity Index (CCI) were associated with a higher risk of developing dementia. The toxoplasmosis patients aged $\geq 65$ years were associated with a higher risk of developing dementia, in comparison to the patients aged 50-64.

\section{Types and sensitivity analysis of dementia after toxoplasmosis}

Table 3 reveals that toxoplasmosis was associated with overall dementia, AD, and other degenerative dementia, with adjusted HR of $2.878(P<0.001), 6.675(P<0.001)$, and $3.162(P<0.001)$, respectively. Toxoplasmosis was noted as being associated with VaD. Table 3 also shows that, after the exclusion of diagnosis within the first year or first 5 years, toxoplasmosis was only associated with other degenerative dementia.

\section{The effects of antiprotozoal medications for toxoplasmosis and the risk of toxoplasmosis \\ Antiprotozoal medication usage for toxoplasmosis was associated with a lower risk than that in the comparison group. Both sulfadiazine and clindamycin, either mono- therapy or combination treatment, were associated with a lower risk of dementia (Table 4).}


Table 1 Characteristics of study population at the baseline

\begin{tabular}{|c|c|c|c|c|c|}
\hline \multirow{2}{*}{$\begin{array}{l}\text { Toxoplasmosis } \\
\text { Variables }\end{array}$} & \multicolumn{2}{|l|}{ With } & \multicolumn{2}{|l|}{ Without } & \multirow[t]{2}{*}{$P$-value } \\
\hline & $n$ & $\%$ & $n$ & $\%$ & \\
\hline Total & 200 & 25.00 & 600 & 75.00 & \\
\hline Gender & & & & & 0.999 \\
\hline Male & 87 & 43.50 & 261 & 43.50 & \\
\hline Female & 113 & 56.50 & 339 & 56.50 & \\
\hline Age (years) & $62.11 \pm 8.88$ & & $63.18 \pm 8.71$ & & 0.135 \\
\hline Age groups (years) & & & & & 0.999 \\
\hline $50-64$ & 131 & 65.50 & 393 & 65.50 & \\
\hline$\geqq 65$ & 69 & 34.50 & 207 & 34.50 & \\
\hline Insurance premium (NT\$) & & & & & $<0.001$ \\
\hline$<18,000$ & 143 & 71.50 & 593 & 98.83 & \\
\hline $18,000-34,999$ & 48 & 24.00 & 7 & 1.17 & \\
\hline$\geqq 35,000$ & 9 & 4.50 & 0 & 0 & \\
\hline Diabetes mellitus & & & & & 0.014 \\
\hline Without & 179 & 89.50 & 493 & 82.17 & \\
\hline With & 21 & 10.50 & 107 & 17.83 & \\
\hline Hypertension & & & & & 0.482 \\
\hline Without & 155 & 77.50 & 479 & 79.83 & \\
\hline With & 45 & 22.50 & 121 & 20.17 & \\
\hline Hyperlipidemia & & & & & 0.357 \\
\hline Without & 196 & 98.00 & 578 & 96.33 & \\
\hline With & 4 & 2.00 & 22 & 3.67 & \\
\hline Coronary artery disease & & & & & 0.885 \\
\hline Without & 183 & 91.50 & 547 & 91.17 & \\
\hline With & 17 & 8.50 & 53 & 8.83 & \\
\hline Obesity & & & & & - \\
\hline Without & 200 & 100 & 600 & 100 & \\
\hline With & 0 & 0 & 0 & 0 & \\
\hline HIV & & & & & $<0.001$ \\
\hline Without & 196 & 98.00 & 596 & 99.33 & \\
\hline With & 4 & 2.00 & 4 & 0.67 & \\
\hline Immune deficiency & & & & & $<0.001$ \\
\hline Without & 190 & 95.00 & 589 & 98.17 & \\
\hline With & 10 & 5.00 & 11 & 1.83 & \\
\hline CCl_R & $0.76 \pm 1.84$ & & $0.69 \pm 1.48$ & & 0.596 \\
\hline Location & & & & & $<0.001$ \\
\hline Northern Taiwan & 68 & 34.00 & 244 & 40.67 & \\
\hline Central Taiwan & 96 & 48.00 & 162 & 27.00 & \\
\hline Southern Taiwan & 26 & 13.00 & 170 & 28.33 & \\
\hline Eastern Taiwan & 8 & 4.00 & 22 & 3.67 & \\
\hline Outlying islands & 2 & 1.00 & 2 & 0.33 & \\
\hline Urbanization level & & & & & 0.003 \\
\hline 1 (highest) & 53 & 26.50 & 208 & 34.67 & \\
\hline 2 & 96 & 48.00 & 260 & 43.33 & \\
\hline 3 & 15 & 7.50 & 39 & 6.50 & \\
\hline 4 (lowest) & 36 & 18.00 & 93 & 15.50 & \\
\hline Level of care & & & & & 0.002 \\
\hline Hospital center & 81 & 40.50 & 220 & 36.67 & \\
\hline Regional hospital & 75 & 37.50 & 172 & 28.67 & \\
\hline Local hospital & 44 & 22.00 & 208 & 34.67 & \\
\hline Department of visits in stud & & & & & \\
\hline
\end{tabular}


Table 1 (continued)

\begin{tabular}{|c|c|c|c|c|c|}
\hline \multirow{2}{*}{$\begin{array}{l}\text { Toxoplasmosis } \\
\text { Variables }\end{array}$} & \multicolumn{2}{|l|}{ With } & \multicolumn{2}{|l|}{ Without } & \multirow[t]{2}{*}{$P$-value* } \\
\hline & $n$ & $\%$ & $n$ & $\%$ & \\
\hline Infection & $1.12 \pm 1.30$ & & $0.85 \pm 1.08$ & & 0.004 \\
\hline Neurology & $2.54 \pm 2.69$ & & $2.03 \pm 2.51$ & & 0.015 \\
\hline Psychiatry & $3.01 \pm 3.47$ & & $2.75 \pm 2.83$ & & 0.289 \\
\hline
\end{tabular}

*Chi-square/Fisher exact test for categorical variables and $t$-test for continuous variables, CCI_RCharlson Comorbidity Index, dementia and HIV removed

\section{Discussion}

In this retrospective cohort study, there are several noteworthy findings. First, patients with toxoplasmosis had a nearly 2.8 -fold increased risk of developing dementia. After the sensitivity analysis, excluding the diagnosis of dementia for the first year and the first 5 years after toxoplasmosis was diagnosed, patients with toxoplasmosis still had a twofold increased risk for developing dementia. Second, the sensitivity analysis revealed that, after excluding the $\mathrm{AD}$ diagnosis in the first year and first 5 years after toxoplasmosis, the association became

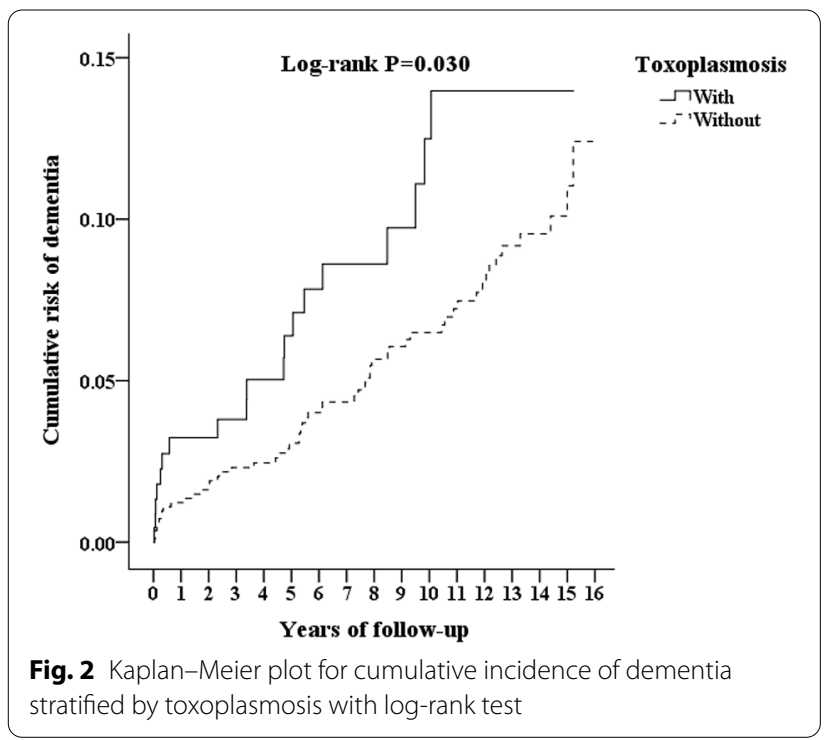

insignificant, but other types of degenerative dementia were still associated with toxoplasmosis. However, other types of degenerative dementia were found to be proportionately higher than $\mathrm{AD}$ and $\mathrm{VaD}$, and most of the community studies revealed that Alzheimer-type dementia is the most common cause of dementia in Taiwan (40-60\% of all dementias), followed by vascular dementia (20-30\% of all dementias) and mixed or other dementias (7-15\%) [39-41]. One possible explanation for this disparity is that some subjects were classified as having other degenerative types of dementia, similar to the findings of previous studies [34, 37]. Third, the usage of the medications sulfadiazine and clindamycin, either in monotherapy or combination treatment, were associated with a lower risk of dementia. To the best of our knowledge, this is the first nationwide, population-based study to investigate the association between toxoplasmosis and the risk of dementia and the effects of antibiotic usage in reducing risk after toxoplasmosis infections.

We also discovered that there were no significant differences in the ratios between the two cohorts (21/200 vs. $56 / 600$ ), or differences between the treatment and nontreatment groups (20/191 vs. 1/9). The difference was only apparent when the duration of follow-up after the exposure to toxoplasmosis was considered, that is, the person-years. This implies that toxoplasmosis might not be the direct cause of dementia, but it could accelerate the process, resulting in early onset of dementia. In addition, antibiotic treatment could attenuate this process. This might indicate that chronic inflammation, instead

Table 2 Factors of dementia using Cox regression and the Fine-Gray competing risk model

\begin{tabular}{|c|c|c|c|c|c|c|c|c|}
\hline \multirow[b]{2}{*}{ Variables } & \multicolumn{4}{|c|}{ No competing risk in the model } & \multicolumn{4}{|c|}{ Competing risk in the model } \\
\hline & Adjusted HR & $95 \% \mathrm{Cl}$ & $95 \% \mathrm{Cl}$ & $P$-value* & Adjusted HR & $95 \% \mathrm{Cl}$ & $95 \% \mathrm{Cl}$ & $P$-value* \\
\hline Toxoplasmosis (reference: without) & 2.570 & 1.511 & 4.347 & $<0.001$ & 2.878 & 1.709 & 4.968 & $<0.001$ \\
\hline Male (reference: female) & 1.841 & 1.123 & 3.018 & 0.001 & 1.989 & 1.235 & 3.310 & $<0.001$ \\
\hline Age $\geq 65$ (reference: age 40-59) & 1.685 & 1.240 & 2.006 & $<0.001$ & 1.703 & 1.259 & 2.034 & $<0.001$ \\
\hline CCl_R & 1.286 & 1.032 & 1.537 & 0.029 & 1.335 & 1.050 & 1.682 & 0.007 \\
\hline
\end{tabular}

${ }^{*}$ Chi-square/Fisher exact test for categorical variables and $t$-test for continuous variables, $H R$ hazard ratio, $\mathrm{Cl}$ confidence interval, $A d j u s t e d ~ H R$ adjusted variables listed in the Table 1, CCI_R Charlson Comorbidity Index, dementia and HIV removed 


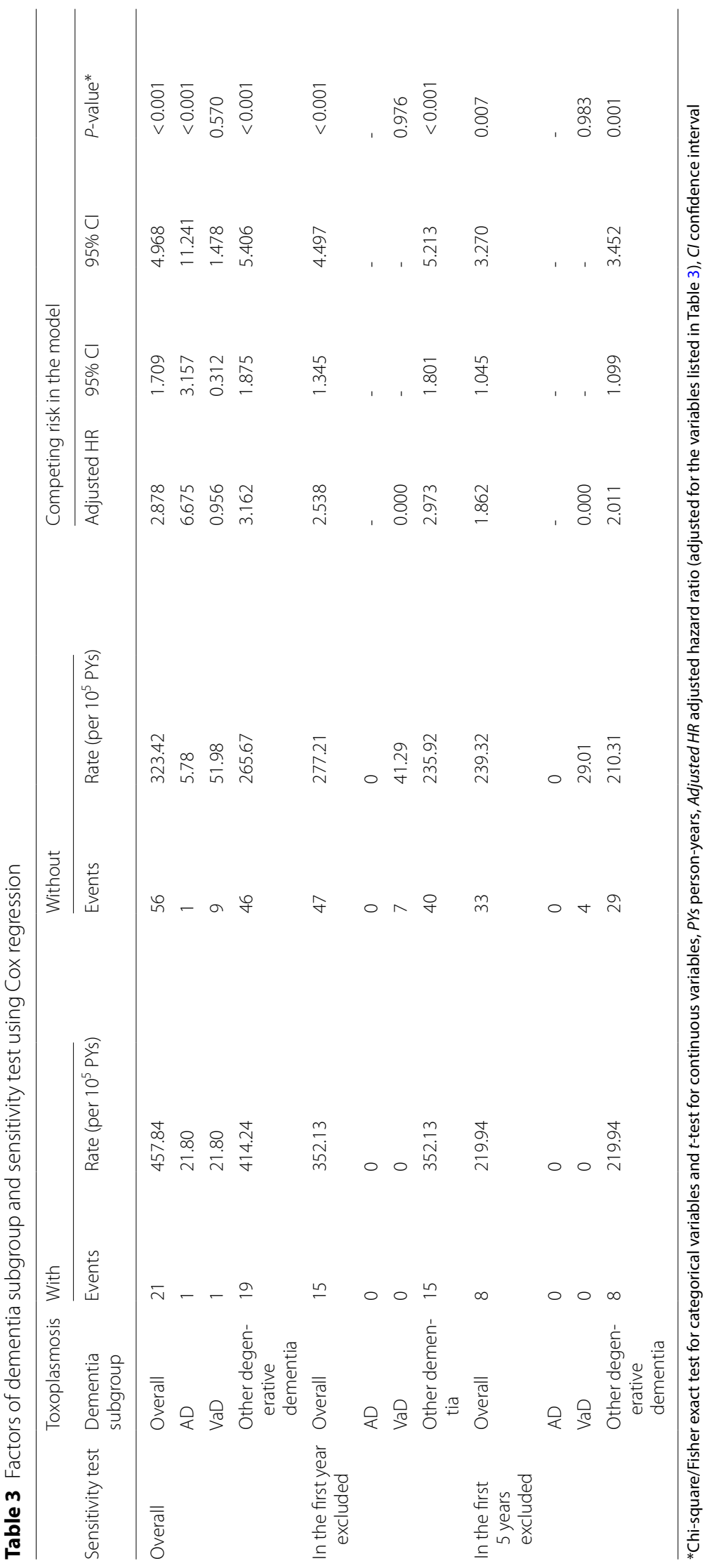


Table 4 Factors of dementia among different models using Cox regression and the Fine-Gray competing risk model

\begin{tabular}{|c|c|c|c|c|c|c|c|c|}
\hline \multirow[t]{2}{*}{ Antibiotics } & \multirow[t]{2}{*}{ Toxoplasmosis subgroup } & \multirow[t]{2}{*}{ Events } & \multirow[t]{2}{*}{ PYS } & \multirow[t]{2}{*}{ Rate (per $10^{5} \mathrm{PYs}$ ) } & \multicolumn{4}{|c|}{ Competing risk in the model } \\
\hline & & & & & Adjusted HR & $95 \% \mathrm{Cl}$ & $95 \% \mathrm{Cl}$ & $P$-value* \\
\hline \multirow[t]{5}{*}{ Sulfadiazine } & With toxoplasmosis, without sulfadiazine & 5 & 1015.10 & 492.56 & Reference & & & \\
\hline & With toxoplasmosis, with sulfadiazine & 16 & 3571.66 & 447.97 & 0.909 & 0.887 & 0.932 & 0.013 \\
\hline & With toxoplasmosis, with sulfadiazine $<30$ days & 5 & 1047.15 & 477.48 & 0.967 & 0.943 & 0.991 & 0.046 \\
\hline & With toxoplasmosis, with sulfadiazine $30-364$ days & 5 & 1257.18 & 397.72 & 0.808 & 0.782 & 0.845 & $<0.001$ \\
\hline & With toxoplasmosis, with sulfadiazine $\geq 365$ days & 6 & 1267.33 & 473.44 & 0.932 & 0.901 & 0.986 & 0.041 \\
\hline \multirow[t]{5}{*}{ Clindamycin } & With toxoplasmosis, without clindamycin & 5 & 879.28 & 568.65 & Reference & & & \\
\hline & With toxoplasmosis, with clindamycin & 16 & 3707.48 & 431.56 & 0.759 & 0.732 & 0.797 & $<0.001$ \\
\hline & With toxoplasmosis, with clindamycin $<30$ days & 5 & 1048.48 & 476.88 & 0.832 & 0.784 & 0.863 & $<0.001$ \\
\hline & With toxoplasmosis, with clindamycin 30-364 days & 5 & 1056.84 & 473.11 & 0.821 & 0.776 & 0.859 & $<0.001$ \\
\hline & With toxoplasmosis, with clindamycin $\geq 365$ days & 6 & 1602.17 & 374.49 & 0.664 & 0.602 & 0.692 & $<0.001$ \\
\hline \multirow{9}{*}{$\begin{array}{l}\text { Sulfadiazine } \\
\text { and / or } \\
\text { Clindamycin }\end{array}$} & With toxoplasmosis, without antibiotics & 1 & 198.15 & 504.67 & Reference & & & \\
\hline & With toxoplasmosis, with any antibiotics & 20 & 4388.61 & 455.72 & 0.927 & 0.894 & 0.950 & 0.022 \\
\hline & With toxoplasmosis, with any antibiotics $<30$ days & 5 & 1030.45 & 485.22 & 0.970 & 0.942 & 0.995 & 0.047 \\
\hline & With toxoplasmosis, with any antibiotics 30-364 days & 7 & 1544.20 & 453.31 & 0.965 & 0.931 & 0.983 & 0.041 \\
\hline & With toxoplasmosis, with any antibiotics $\geq 365$ days & 8 & 1813.96 & 441.02 & 0.864 & 0.803 & 0.899 & $<0.001$ \\
\hline & With toxoplasmosis, with both antibiotics & 12 & 2890.53 & 415.15 & 0.812 & 0.694 & 0.872 & $<0.001$ \\
\hline & With toxoplasmosis, with both antibiotics $<30$ days & 5 & 1065.18 & 469.40 & 0.853 & 0.793 & 0.901 & $<0.001$ \\
\hline & With toxoplasmosis, with both antibiotics 30-364 days & 3 & 769.82 & 389.70 & 0.750 & 0.615 & 0.830 & $<0.001$ \\
\hline & With toxoplasmosis, with both antibiotics $\geq 365$ days & 4 & 1055.54 & 378.95 & 0.721 & 0.594 & 0.825 & $<0.001$ \\
\hline
\end{tabular}

*Chi-square/Fisher exact test for categorical variables and $t$-test for continuous variables, $P Y_{s}$ person-years, Adjusted $H R$ adjusted hazard ratio (adjusted for the variables listed in Table 1), Cl confidence interval

of the toxoplasmic infection itself, contributes to the process in the development of dementia.

In previous studies, the brain was found to be the main target organ in $T$. gondii infection, and may cause life-threatening encephalitis in immunocompromised patients [42]. In healthy individuals, the tachyzoites of the parasite can be cleaned by the cellular immune response in the proliferative stage of the systemic infection [43]. In an infected mouse brain model, interferongamma (IFN- $\gamma$ ) produced by lymphocytes, microglial cells, and blood-derived macrophages mediated the cell immune response to the proliferating tachyzoites [44]. In addition, IFN- $\gamma$ was found to activate astrocytes which inhibit tachyzoite replication by nitric oxide (NO) production [44]. Microglia are also resident innate immune cells in the CNS and are the main cause of the inflammatory process. Uncontrolled activation of microglial cells may cause neurotoxicity due to the release of inflammatory cytokines, $\mathrm{NO}$, or superoxide (SOD). In addition to acute toxoplasmosis caused by tachyzoites, bradyzoites of the parasite can produce a tissue cyst and slowly replicate in the brain or muscles, leading to latent toxoplasmosis [43]. Although tachyzoites can induce more obvious inflammatory cytokine production than bradyzoites [44], the dormant parasite can resume pathogenic activity and kill a host with immune deficiency. Latent toxoplasmosis is asymptomatic in normal conditions. However, in contrast to acute toxoplasmosis, latent toxoplasmosis might cause a slow and cumulative effect that decreases psychomotor performance [45]. Early animal models already demonstrated pathological changes in the cyst-containing region of the brain in mice, including the granulomatous change in the perivascular areas and necrotic tissue deposition with vascular sclerosis [46].

Torres et al. designed another mouse model and argued that the study, by Möhle et al., has not evaluated the advanced signs as $T$. gondii-driven cerebral amyloid angiopathy (CAA). In addition, there was also $A \beta$ immunoreactivity co-localized with the $T$. gondii cysts as early as day 15 post-infection and widespread $A \beta$ immunoreactivity. They were detected in other areas of the brain where they did not co-localize with cysts at days 60 to 90 post-infection [47]. Moreover, Torres et al. pointed out that A $\beta$ immunoreactivity may lead to $N$-methyl- $d$-aspartate receptor (NMDAR) loss. In the CNS, glutamate plays a role in neuron excitation and could be endocytosed or released at the synapse through NMDAR on neural cells. Therefore, NMDAR plays an important role in the synaptic connection which controls the function of learning and memory. NMDAR dysfunction is strongly associated with AD [48]. There was also strong evidence that an NMDAR antagonist could prevent neuronal dysfunction 
through $A \beta$ immunoreactivity [49]. However, some studies found that countries with high seropositivity of T. gondii did not have a higher prevalence of AD. For example, in the 1970s, the seroprevalence in France was 70\% [1], but only 3\% prevalence of AD was noted in people older than 60 years in 2012 [50]. Möhle et al. (2016) reported a mouse model study and discovered that there were reduced $\mathrm{A} \beta$ plaques in $T$. gondii-infected mice compared to the non-infected mice [51]. The association between toxoplasmosis and $\mathrm{AD}$, as well as the underlying mechanisms, has yet to be clarified.

Our study has several strengths: First, we used Taiwan's NHIRD, which is a valuable resource to address this issue in a nationwide population. Second, several previous studies have demonstrated the accuracy and validity of several diagnoses of neuropsychiatric disorders in the NHIRD, such as Tourette syndrome [52], stroke [31, 53-55], sleep apnea [56], and major depressive disorder [57]. In addition, as previously mentioned, the in-hospital licensed medical records technicians and the NHI Administration would have verified the diagnoses in the claims dataset $[22,35]$ for the diagnosis. Third, previous studies have also demonstrated concordance between Taiwan's National Health Survey and the NHIRD on a variety of diagnoses [58], medication usage [58], and health system utilization $[58,59]$. Therefore, this study was conducted using a large, nationwide, and reliable database for the association between toxoplasmosis and psychiatric morbidities in an Asian country.

The present study has several limitations that warrant consideration. First, similar to previous studies, not all data were recorded in the NHIRD, and we were unable to evaluate family history, neurological severity, types, laboratory parameters, the availability of rehabilitation, or additional examination findings (e.g., neuroimaging). Therefore, the lack of data on the clinical and radiological course and treatment of the disease was a limitation. Second, other factors, such as genetic, psychosocial, and environmental factors, were not included in the dataset. However, the present study covers all of Taiwan's hospitals and $>99 \%$ of the Taiwanese population during a 15-year period, thereby increasing the likelihood that our data are valid and representative. Third, the recorded prevalence of Toxoplasma infection in Taiwan was about $10 \%$ in 2006 (https://nidss.cdc.gov.tw), but this was with a focus only on pregnant women, and it did not represent the general prevalence in the total population. Therefore, we were not able correlate the current prevalence of dementia with the prevalence of toxoplasmosis in the past. Fourth, there were very few non-treatment patients in our study, and we used a one-sided test to analyze the significance between the treatment and non-treatment groups. This limits the generalizability of the results regarding antibiotic effects and their association with reduced risk of dementia. Further evaluations are needed using randomized clinical trials or observational studies in a larger population.

\section{Conclusions}

To the best of our knowledge, we have provided the first evidence that toxoplasmosis is associated with dementia in Taiwan. The results show that the usage of antibiotics for toxoplasmosis might be beneficial in attenuating the risk of dementia for patients with toxoplasmosis. Clinicians should focus more attention on the risk of dementia in patients with toxoplasmosis.

\section{Abbreviations \\ A $\beta$ : Amyloid $\beta ;$ AD: Alzheimer's disease; AIDS: Acquired immune deficiency syndrome; ALS: Amyotrophic lateral sclerosis; CAA: Cerebral amyloid angiopa- thy; CAD: Coronary artery disease; Cl: Confidence interval; CNS: Central nerv- ous system; DDD: Defined daily dose; DM: Diabetes mellitus; HD: Huntington's disease; HIV: Human immunodeficiency virus; HR: Hazard ratio; HWDC: Health and Welfare Data Science Center; ICD-9-CM: International Classification of Disease, Ninth Revision, Clinical Modification; IFN- - : Interferon-gamma; LHID: Longitudinal Health Insurance Database; MOHW: Ministry of Health and Welfare; MS: Multiple sclerosis; NHI: National Health Insurance; NHIRD: National Health Insurance Research Database; NMDAR: N-methyl-D-aspartate receptor; NO: Nitric oxide; NT\$: New Taiwan dollars; PCR: Polymerase chain reaction; PD: Parkinson's disease; SOD: Superoxide; T. gondii: Toxoplasma gondii; VaD: Vascular dementia.}

\section{Supplementary Information}

The online version contains supplementary material available at https://doi. org/10.1186/s13071-021-04928-7.

Additional file 1: Figure S1. The flowchart for the comparison of patients with toxoplasmosis with and without antibiotic treatment

Additional file 2: Figure S2. The Kaplan-Meier survival analysis in toxoplasmosis patients with or without antibiotic treatment. In the comparison of the two groups, the difference was statistically significant

Additional file 3: Table S1. International Classification of Diseases, Ninth Revision, Clinical Modification codes in this study

Acknowledgements

The authors thank Taiwan's Health and Welfare Data Science Center and Ministry of Health and Welfare (HWDC, MOHW) for the provision of the National Health Insurance Research Database.

\section{Authors' contributions}

NST and HYY conceived and designed the study, and wrote the first draft manuscript. RYS, CYL, and CCY helped in implementation of this study. WCC and $\mathrm{CHC}$ performed research data collection and statistical analyses. All authors read and approved the final manuscript.

\section{Funding}

Project financial support was provided by the Medical Affairs Bureau, the Ministry of Defense of Taiwan (MAB-107-084 and MND-MAB-110-087), the Tri-Service General Hospital Research Foundation (TSGH-C108-003, TSGHC108-151, TSGH-B-109-010, TSGH-E-110240, and TSGH-B-110-012), and the Taoyuan Armed Forces General Hospital (TYAFGH-A-110020). The sponsor had no role in the study design, data collection and analysis, decision to publish, or preparation of the manuscript. 


\section{Availability of data and materials}

The datasets on the study population that were obtained from the NHIRD (http://nhird.nhri.org.tw/en/index.html) are maintained in the NHIRD (http:// nhird.nhri.org.tw/). The National Health Research Institutes (NHRI) is a nonprofit foundation established by the government. Only citizens of Taiwan who fulfill the requirements for conducting research projects are eligible to apply for the NHIRD. The use of the NHIRD is limited to research purposes only. Applicants must follow the Computer-Processed Personal Data Protection Act (http://www.winklerpartners.com/?p=987) and the related regulations of the National Health Insurance Administration and NHRI, and an agreement must be signed by the applicant and their supervisor upon application submission. All applications are reviewed for approval of data release.

\section{Declarations}

\section{Ethics approval and consent to participate}

This study was approved by the Institutional Review Board of the Tri-Service General Hospital (TSGH IRB No. 2-107-05-026).

\section{Consent for publication}

Because the patient identifiers were encrypted before their data were used for research purposes to protect confidentiality, the requirement for written or verbal consent from patients for data linkage was waived.

\section{Competing Interests}

The authors declare no competing interests.

\section{Author details}

${ }^{1}$ Division of Clinical Pathology, Department of Pathology, Tri-Service General Hospital, School of Medicine, National Defense Medical Center, Taipei, Taiwan. ${ }^{2}$ Department of Medical Research, Tri-Service General Hospital, National Defense Medical Center, Taipei, Taiwan. ${ }^{3}$ School of Public Health, National Defense Medical Center, Taipei, Taiwan. ${ }^{4}$ Graduate Institute of Life Sciences, National Defense Medical Center, Taipei, Taiwan. ${ }^{5}$ Taiwanese Injury Prevention and Safety Promotion Association, Taipei, Taiwan. ${ }^{6}$ Graduate Institute of Aerospace and Undersea Medicine, School of Medicine, National Defense Medical Center, Taipei, Taiwan. ${ }^{7}$ Department of Psychiatry, Taoyuan Armed Forces General Hospital, Taoyuan, Taiwan. ${ }^{8}$ Department of Psychiatry, Tri-Service General Hospital, School of Medicine, National Defense Medical Center, Taipei, Taiwan. ${ }^{9}$ Student Counseling Center, National Defense Medical Center, Taipei, Taiwan.

Received: 29 April 2021 Accepted: 5 August 2021

Published online: 28 August 2021

\section{References}

1. Robert-Gangneux F, Darde ML. Epidemiology of and diagnostic strategies for toxoplasmosis. Clin Microbiol Rev. 2012;25:264-96.

2. Tenter AM, Heckeroth AR, Weiss LM. Toxoplasma gondii: from animals to humans. Int J Parasitol. 2000;30:1217-58.

3. Wilking H, Thamm M, Stark K, Aebischer T, Seeber F. Prevalence, incidence estimations, and risk factors of Toxoplasma gondii infection in Germany: a representative, cross-sectional, serological study. Sci Rep. 2016;6:22551.

4. Center for Disease Control. Introduction to Toxoplasmosis. https://www. cdc.gov.tw/File/Get/sqrAKrJg_Uq8Ki5BOHtO3g?path=CbQtr9efAo_ 2E10ZEstd2J5QKlu34aEmG6X1BdPpNeDQ2CtHDScOGTGOxIBjpnXUee o3R86xYnUzhEWsIPu-qA\&name=G5tHATu3PN9vCZCYnPRueSNsD98p1 $\mathrm{k}$ mxpv6tOg-nNrs. 2010. Accessed 11 Feb 2021.

5. American Psychiatric Association. Diagnostic and statistical manual of mental disorders, fourth edition, text-revision. Philadelphia: American Psychiatric Association Publishing; 1994.

6. Hickey EM, Bourgeois MC. Dementia: person-centered assessment and intervention. Abingdon: Routledge; 2018.

7. Association A. 2015 Alzheimer's disease facts and figures. Alzheimers Dement. 2015;11:332-84.

8. Zhou L, Miranda-Saksena M, Saksena NK. Viruses and neurodegeneration. Virol J. 2013:10:172

9. Mattson MP. Infectious agents and age-related neurodegenerative disorders. Ageing Res Rev. 2004;3:105-20.
10. Henriquez SA, Brett R, Alexander J, Pratt J, Roberts CW. Neuropsychiatric disease and Toxoplasma gondii infection. NeurolmmunoModulation. 2009:16:122-33.

11. Xiao J, Prandovszky E, Kannan G, Pletnikov MV, Dickerson F, Severance EG, et al. Toxoplasma gondii: biological parameters of the connection to schizophrenia. Schizophr Bull. 2018;44:983-92.

12. Gajewski PD, Falkenstein M, Hengstler JG, Golka K. Toxoplasma gondii impairs memory in infected seniors. Brain Behav Immun. 2014;36:193-9.

13. Nimgaonkar VL, Yolken RH, Wang T, Chang CC, McClain L, McDade E, et al. Temporal cognitive decline associated with exposure to infectious agents in a population-based, aging cohort. Alzheimer Dis Assoc Disord. 2016:30:216-22.

14. McConkey GA, Martin HL, Bristow GC, Webster JP. Toxoplasma gondii infection and behavior-location, location, location? J Exp Biol. 2013;216:113-9.

15. Hamdani N, Daban-Huard C, Lajnef M, Gadel R, Le Corvoisier P, Delavest $M$, et al. Cognitive deterioration among bipolar disorder patients infected by Toxoplasma gondii is correlated to interleukin 6 levels. J Affect Disord. 2015;179:161-6.

16. Carruthers VB, Suzuki Y. Effects of Toxoplasma gondii infection on the brain. Schizophr Bull. 2007;33:745-51.

17. Nayeri Chegeni T, Sarvi S, Moosazadeh M, Sharif M, Aghayan SA, Amouei A, et al. Is Toxoplasma gondii a potential risk factor for Alzheimer's disease? a systematic review and meta-analysis. Microb Pathog. 2019;137:103751.

18. Bayani M, Riahi SM, Bazrafshan N, Ray Gamble H, Rostami A. Toxoplasma gondii infection and risk of Parkinson and Alzheimer diseases: a systematic review and meta-analysis on observational studies. Acta Trop. 2019;196:165-71

19. Mahami-Oskouei M, Hamidi F, Talebi M, Farhoudi M, Taheraghdam AA Kazemi T, et al. Toxoplasmosis and Alzheimer: Can Toxoplasma gondii really be introduced as a risk factor in etiology of Alzheimer? Parasitol Res. 2016;115:3169-74.

20. Perry CE, Gale SD, Erickson L, Wilson E, Nielsen B, Kauwe J, et al. Seroprevalence and serointensity of latent Toxoplasma gondii in a sample of elderly adults with and without Alzheimer disease. Alzheimer Dis Assoc Disord. 2016:30:123-6.

21. Ho Chan WS. Taiwan's healthcare report 2010. EPMA J. 2010;1:563-85.

22. Hsieh C-Y, Su C-C, Shao S-C, Sung S-F, Lin S-J, Kao Yang Y-H, et al. Taiwan's National Health Insurance Research Database: past and future. Clin Epidemiol. 2019;11:349-58.

23. Yang CC, Chien WC, Chung CH, Liu YP, Yeh CB, Chen KH, et al. No association between human immunodeficiency virus infections and dementia: a Nationwide Cohort Study In Taiwan. Neuropsychiatr Dis Treat. 2019;15:3155-66.

24. Chen TY, Huang $\mathrm{CH}$, Chung $\mathrm{CH}$, Mao WC, Yeh $\mathrm{CB}$, Yang CCH, et al. Sex and age differences in the association between anxiety disorders and narcolepsy: a nationwide population-based case control study. J Affect Disord. 2020;264:130-7.

25. Lin $\mathrm{CH}$, Chien WC, Chung $\mathrm{CH}$, Chiang $\mathrm{CP}$, Wang WM, Chang HA, et al. Increased risk of dementia in patients with genital warts: a nationwide cohort study in Taiwan. J Dermatol. 2020:47:503-11.

26. Lin YC, Chen TY, Chien WC, Chung CH, Chang HA, Kao YC, et al. Stimulants associated with reduced risk of hospitalization for motor vehicle accident injury in patients with obstructive sleep apnea-a nationwide cohort study. BMC Pulm Med. 2020;20:28.

27. Liu YP, Chien WC, Chung CH, Chang HA, Kao YC, Tzeng NS. Are anticholinergic medications associated with increased risk of dementia and behavioral and psychological symptoms of dementia? A nationwide 15-year follow-up cohort study in Taiwan. Front Pharmacol. 2020;11:30.

28. Wan FJ, Chien WC, Chung CH, Yang YJ, Tzeng NS. Association between traumatic spinal cord injury and affective and other psychiatric disordersa nationwide cohort study and effects of rehabilitation therapies. J Affect Disord. 2020;265:381-8.

29. Wang DS, Chung CH, Chang HA, Kao YC, Chu DM, Wang CC, et al. Association between child abuse exposure and the risk of psychiatric disorders: a nationwide cohort study in Taiwan. Child Abuse Negl. 2020;101:104362.

30. Yeh TC, Chien WC, Chung CH, Liang CS, Chang HA, Kao YC, et al. Psychiatric disorders after traumatic brain injury: a nationwide population-based cohort study and the effects of rehabilitation therapies. Arch Phys Med Rehabil. 2020;101:822-31. 
31. Cheng CL, Kao YH, Lin SJ, Lee CH, Lai ML. Validation of the National Health Insurance Research Database with ischemic stroke cases in Taiwan. Pharmacoepidemiol Drug Saf. 2011;20:236-42

32. Hsieh CY, Chen CH, Li CY, Lai ML. Validating the diagnosis of acute ischemic stroke in a national health insurance claims database. J Formos Med Assoc. 2015;114:254-9.

33. Liang JA, Sun LM, Muo CH, Sung FC, Chang SN, Kao CH. The analysis of depression and subsequent cancer risk in Taiwan. Cancer Epidemiol Biomarkers Prev. 2011:20:473-5.

34. Tzeng NS, Chung CH, Yeh CB, Huang RY, Yuh DY, Huang SY, et al. Are chronic periodontitis and gingivitis associated with dementia? A nationwide, retrospective, matched-cohort study in Taiwan. Neuroepidemiology. 2016;47:82-93.

35. Ministry of Justice. National Health Insurance Reimbursement Regulations. 2018. https://law.moj.gov.tw/LawClass/LawAll.aspx?pcode=L0060 006. Accessed 19 Jul 2021.

36. Chao PC, Chien WC, Chung CH, Chu CW, Yeh CB, Huang SY, et al. Cognitive enhancers associated with decreased risk of injury in patients with dementia: a nationwide cohort study in Taiwan. J Investig Med. 2018:66:684-92.

37. Tzeng NS, Chung CH, Lin FH, Huang CF, Yeh CB, Huang SY, et al. Magnesium oxide use and reduced risk of dementia: a retrospective, nationwide cohort study in Taiwan. Curr Med Res Opin. 2018;34:163-9.

38. Tzeng NS, Chung CH, Lin FH, Chiang CP, Yeh CB, Huang SY, et al. Antiherpetic medications and reduced risk of dementia in patients with herpes simplex virus infections-a nationwide, population-based cohort study in Taiwan. Neurotherapeutics. 2018;15:417-29.

39. Liu HC, Lin KN, Teng EL, Wang SJ, Fuh JL, Guo NW, et al. Prevalence and subtypes of dementia in Taiwan: a community survey of 5297 individuals. J Am Geriatr Soc. 1995;43:144-9.

40. Lin RT, Lai CL, Tai CT, Liu CK, Yen YY, Howng SL. Prevalence and subtypes of dementia in southern Taiwan: impact of age, sex, education, and urbanization. J Neurol Sci. 1998;160:67-75.

41. Liu CK, Lai CL, Tai CT, Lin RT, Yen YY, Howng SL. Incidence and subtypes of dementia in southern Taiwan: impact of socio-demographic factors. Neurology. 1998;50:1572-9.

42. Creuzet C, Robert F, Roisin MP, Van Tan H, Benes C, Dupouy-Camet J, et al. Neurons in primary culture are less efficiently infected by Toxoplasma gondii than glial cells. Parasitol Res. 1998;84:25-30.

43. Denkers EY, Gazzinelli RT. Regulation and function of T-cell-mediated immunity during Toxoplasma gondii infection. Clin Microbiol Rev. 1998:11:569-88.

44. Suzuki Y, Orellana MA, Schreiber RD, Remington JS. Interferon-gamma: the major mediator of resistance against Toxoplasma gondii. Science. 1988;240:516-8

45. Havlicek J, Gasova ZG, Smith AP, Zvara K, Flegr J. Decrease of psychomotor performance in subjects with latent "asymptomatic" toxoplasmosis. Parasitology. 2001;122:515-20.

46. Werner H, Masihi KN, Senk U. Latent Toxoplasma-infection as a possible risk factor for CNS-disorders. Zentralbl Bakteriol Mikrobiol Hyg A. 1981;250:368-75.
47. Torres L, Robinson SA, Kim DG, Yan A, Cleland TA, Bynoe MS. Toxoplasma gondii alters NMDAR signaling and induces signs of Alzheimer's disease in wild-type, C57BL/6 mice. J Neuroinflammation. 2018;15:57.

48. Foster TC, Kyritsopoulos C, Kumar A. Central role for NMDA receptors in redox mediated impairment of synaptic function during aging and Alzheimer's disease. Behav Brain Res. 2017;322:223-32.

49. Gunn AP, Wong BX, Johanssen T, Griffith JC, Masters CL, Bush Al, et al. Amyloid-beta peptide abeta3pe-42 induces lipid peroxidation, membrane permeabilization, and calcium influx in neurons. J Biol Chem. 2016;291:6134-45.

50. Takizawa C, Thompson PL, van Walsem A, Faure C, Maier WC. Epidemiological and economic burden of Alzheimer's disease: a systematic literature review of data across Europe and the United States of America. J Alzheimers Dis. 2015:43:1271-84.

51. Mohle L, Israel N, Paarmann K, Krohn M, Pietkiewicz S, Muller A, et al. Chronic Toxoplasma gondii infection enhances beta-amyloid phagocytosis and clearance by recruited monocytes. Acta Neuropathol Commun. 2016;4:25.

52. Chou IC, Lin HC, Lin CC, Sung FC, Kao CH. Tourette syndrome and risk of depression: a population-based cohort study in Taiwan. J Dev Behav Pediatr. 2013;34:181-5.

53. Cheng $\mathrm{CL}$, Chien HC, Lee $\mathrm{CH}$, Lin SJ, Yang YH. Validity of in-hospital mortality data among patients with acute myocardial infarction or stroke in National Health Insurance Research Database in Taiwan. Int J Cardiol. 2015;201:96-101.

54. Sung SF, Hsieh CY, Lin HJ, Chen YW, Yang YH, Li CY. Validation of algorithms to identify stroke risk factors in patients with acute ischemic stroke, transient ischemic attack, or intracerebral hemorrhage in an administrative claims database. Int J Cardiol. 2016;215:277-82.

55. Tseng HP, Lin FJ, Chen PT, Mou CH, Lee SP, Chang CY, et al. Derivation and validation of a discharge disposition predicting model after acute stroke. J Stroke Cerebrovasc Dis. 2015;24:1179-86.

56. Su VY, Liu CJ, Wang HK, Wu LA, Chang SC, Perng DW, et al. Sleep apnea and risk of pneumonia: a nationwide population-based study. CMAJ. 2014;186:415-21.

57. Wu CS, Kuo CJ, Su CH, Wang SH, Dai HJ. Using text mining to extract depressive symptoms and to validate the diagnosis of major depressive disorder from electronic health records. J Affect Disord. 2020:260:617-23.

58. Wu CS, Lai MS, Gau SS, Wang SC, Tsai HJ. Concordance between patient self-reports and claims data on clinical diagnoses, medication use, and health system utilization in Taiwan. PLoS ONE. 2014;9:e112257.

59. Yu ST, Chang HY, Lin MC, Lin YH. Agreement between self-reported and health insurance claims on utilization of health care: a population study. J Clin Epidemiol. 2009;62:1316-22.

\section{Publisher's Note}

Springer Nature remains neutral with regard to jurisdictional claims in published maps and institutional affiliations.

Ready to submit your research? Choose BMC and benefit from

- fast, convenient online submission

- thorough peer review by experienced researchers in your field

- rapid publication on acceptance

- support for research data, including large and complex data types

- gold Open Access which fosters wider collaboration and increased citations

- maximum visibility for your research: over 100M website views per year

At $\mathrm{BMC}$, research is always in progress.

Learn more biomedcentral.com/submissions 